\title{
1 A Shigella type 3 effector protein co-opts host inositol pyrophosphates for activity
}

2

3 Thomas E. Wood, ${ }^{1,2, \dagger}$ Jessica M. Yoon, ${ }^{3,5, \dagger}$ Heather D. Eshleman, ${ }^{1,2,6}$ Daniel J. Slade, ${ }^{4}$ Cammie F.

4 Lesser, ${ }^{1,2}$ Marcia B. Goldberg ${ }^{1,2, *}$

5 'Department of Medicine, Division of Infectious Diseases, Massachusetts General Hospital, Boston, 6 Massachusetts, USA.

$7 \quad{ }^{2}$ Department of Microbiology, Blavatnik Institute, Harvard Medical School, Boston, Massachusetts, 8 USA.

$9 \quad{ }^{3}$ Department of Molecular and Cellular Biology, Harvard University, Cambridge, Massachusetts, USA.

$10{ }^{4}$ Department of Biochemistry, Virginia Polytechnic Institute and State University, Blacksburg, Virginia,

11 USA

12 5resent address: Office of Response and Recovery, Federal Emergency Management Agency,

13 Washington, D.C., USA

$14 \quad{ }^{6}$ Present address: Lexical Intelligence, LLC, Rockville, Maryland, USA

16 These authors contributed equally to this work.

17 For correspondence: E-mail: marcia.goldberg@ mgh.harvard.edu Tel: +1 617-525-4820. 


\section{$18 \quad$ Abstract}

19

20

Shigella spp. cause diarrhea by invading human intestinal epithelial cells. Effector proteins delivered into target host cells by the Shigella type 3 secretion system modulate host signaling pathways and processes in a manner that promotes infection. The effector OspB activates mTOR, the central cellular regulator of growth and metabolism, and potentiates the inhibition of mTOR by rapamycin. The net effect of OspB on cell monolayers is cell proliferation at infectious foci. To gain insights into the mechanism by which OspB potentiates rapamycin inhibition of mTOR, we employ in silico analyses to identify putative catalytic residues of $\mathrm{OspB}$ and show that a conserved cysteine-histidine dyad is required for this activity of OspB. In a screen of an over-expression library in Saccharomyces cerevisiae, we identify a dependency of OspB activity on inositol pyrophosphates, a class of eukaryotic secondary messengers that are distinct from the inositol phosphates known to act as cofactors for bacterial cysteine proteases. We show that inositol pyrophosphates are required for OspB activity not only in yeast, but also in mammalian cells - the first demonstration of inositol pyrophosphates being required for virulence of a bacterial pathogen in vivo. 


\section{Introduction}

Shigella spp. are the etiological agents of bacillary dysentery, accounting for one of the leading causes of mortality from diarrheal disease (Khalil et al., 2018). These Gram-negative bacterial pathogens invade the intestinal epithelium, establishing a replicative niche within colonic epithelial cells and triggering an acute inflammatory immune response (Carayol \& Tran Van Nhieu, 2013). The type 3 secretion system (T3SS) is required for S. flexneri infection, facilitating invasion and bacterial multiplication through the delivery into host cells of effector proteins that subvert cellular signaling pathways. Effector proteins also promote the cell-to-cell spread of intracellular Shigella, whereby it disseminates throughout the intestinal epithelium (Agaisse, 2016).

The T3SS effector protein OspB restricts the intercellular spread of S. flexneri by activating mammalian target of rapamycin (mTOR), the master regulator of cellular growth (Lu et al., 2015). OspB-mediated activation of mTOR promotes survival and proliferation of infected host epithelial cells, which may supply further niches for the replicating bacteria. Other phenotypes have also been described for OspB, such as dampening the innate immune response via MAP kinase and NF-kB signaling and modulating cytokine release (Ambrosi et al., 2015; Fukazawa et al., 2008; Zurawski, Mumy, Faherty, McCormick, \& Maurelli, 2009).

To gain insights into the mechanisms of OspB activity, we explored similarities among OspB and its homologs and conducted a genome-wide screen for host factors necessary for its activity. We identified the catalytic residues of OspB through bioinformatic analysis and assessed their requirement for OspB activity. Exploiting a Saccharomyces cerevisiae expression system, we determined that inositol phosphate biosynthesis is a process critical to OspB activity. Genetic analysis of this pathway demonstrated that inositol pyrophosphates, rather than inositol phosphates, are necessary for OspB function, suggesting a role for inositol pyrophosphates during bacterial infection. 


\section{Results and Discussion}

\section{OspB exhibits structural homology to cysteine proteases}

To improve our understanding of the mechanism of action of OspB, we performed in silico analyses of its amino acid sequence. This analysis revealed that OspB shares $27-30 \%$ sequence identity with the cysteine protease domains (CPD) of the large clostridial cytotoxins TcdA and TcdB of Clostridioides difficile and the multifunctional autoprocessing repeats-in-toxin (MARTX) RtxA toxins of Vibrio cholerae and V. vulnificus (Figure 1a). TcdA, TcdB and RtxA are modular toxins that upon endocytosis into the host cell undergo autoproteolysis, which releases toxin domains that subvert cellular processes by inducing actin depolymerization and altering GTPase signaling (Fullner \& Mekalanos, 2000; Just et al., 1995). In contrast to these large cytotoxins, OspB is small (288 amino acids; $32 \mathrm{kD}$ ) and in cells, we found no evidence for OspB autoprocessing (Figure S1).

The cysteine and histidine residues required for the proteolytic activity of the CPDs are conserved in OspB and the orthologous T3SS effector protein of V. parahaemolyticus VPA1380 (Calder et al., 2014; Egerer, Giesemann, Jank, Satchell, \& Aktories, 2007; Sheahan, Cordero, \& Satchell, 2007) (Figure 1a). Indeed, the tertiary structure of OspB can be modelled on the CPDs of RtxA and TcdA with 96\% and $62 \%$ confidence, respectively, with conservation of the positions of their catalytic residues with C184 and H144 of OspB (Figure 1b). Mutagenesis studies of TcdA showed that in addition to C700 and H655, D589 is required for autoprocessing through proton abstraction from the histidine in the active site, whereas the analogous aspartic acid residue in RtxA is not required for its activity (Prochazkova et al., 2009; Pruitt et al., 2009). Rather, the catalytic residues of RtxA comprise solely of the C3568-H3519 dyad. In OspB an aspartic acid residue (D108) is present at the equivalent position of D589 ${ }^{\mathrm{TcdA}}$ and was therefore a candidate for involvement in catalysis (Figure 1b).

The alignment of OspB with RtxA and TcdA suggested that OspB residues C184 and H144, and potentially D108, may be required for OspB activity. A quantitative assay in yeast strains expressing $S$. flexneri effector proteins previously demonstrated that OspB causes growth inhibition of yeast in the presence of the cellular stressor caffeine (Slagowski, Kramer, Morrison, LaBaer, \& Lesser, 2008). We 
utilized this assay to probe the role of the putative catalytic residues in OspB activity. Whereas expression of wild type OspB elicits a drastic growth defect in the presence of caffeine, mutation of either C184 or H144 completely abrogated toxicity (Figure 1c). On the other hand, alanine substitution of D108 did not rescue yeast growth. These results indicate that the function of OspB requires both a cysteine and a histidine residue and is independent of D108, similar to the cysteine-histidine catalytic dyad of the CPD of RtxA.

Among the effects of caffeine on cellular processes, in yeast, inhibition of TOR is described as an important mode of action for this compound (Reinke, Chen, Aronova, \& Powers, 2006). To determine whether TOR plays a role in OspB-dependent growth inhibition of yeast, we replaced caffeine in the media with rapamycin, which unlike caffeine is a specific inhibitor of TOR. As with caffeine, the presence of rapamycin sensitized yeast to growth inhibition by OspB in a manner that depended on residues C184 and H144 (Figure 1c).

These results indicate that the activity of OspB in yeast results in hypersensitivity to TOR inhibition, either by caffeine or by rapamycin, which mirrors our previous findings that OspB potentiates rapamycin inhibition of growth in mammalian cells ( $\mathrm{Lu}$ et al., 2015). Functional analysis of point mutations in OspB derivatives shows that this modulation of the TOR pathway depends on the predicted catalytic dyad of $\mathrm{C} 184$ and $\mathrm{H} 144$, bolstering our predictions for the tertiary structure of OspB as a structural homolog of the cysteine protease domains of several modular bacterial toxins. Furthermore, the presence of similar OspB-dependent phenotypes in both yeast and mammalian cells with respect to sensitization to TOR inhibition demonstrates that yeast present a reasonable model for investigating the mechanism of OspB activity.

\section{In yeast, inositol pyrophosphate biosynthesis is necessary for OspB-mediated growth inhibition}

With the goal of identifying factors required for OspB activity, we screened a S.cerevisiae over-expression library (Sopko et al., 2006) for genes that rescued OspB inhibition of yeast growth in the presence of caffeine (Figure 2a). The OspB-mediated growth defect was suppressed by over-expression of several genes, including two in the inositol phosphate biosynthetic pathway, DDP1 
bioRxiv preprint doi: https://doi.org/10.1101/2021.09.01.458261; this version posted September 1, 2021. The copyright holder for this preprint (which was not certified by peer review) is the author/funder, who has granted bioRxiv a license to display the preprint in perpetuity. It is made available under aCC-BY 4.0 International license.

and SIW14 (Table S1). Of note, the CPDs of RtxA and TcdA bind inositol hexakisphosphate (IP 6 ) (Figure 1b) and require it for cysteine protease activity in vitro (Prochazkova \& Satchell, 2008; Reineke et al., 2007). Therefore, we investigated whether OspB also recruits an inositol phosphate species as a cofactor. Introduction of a plasmid over-expressing either DDP1 or SIW14 into a yeast strain that constitutively produces OspB resulted in complete rescue of the OspB-mediated growth defect, whereas the empty over-expression vector control had no effect (Figure 2b). DDP1 and SIW14 each encode a phosphatase that hydrolyzes $\beta$-phosphates of inositol pyrophosphate species (Kilari, Weaver, Shears, \& Safrany, 2013; Safrany et al., 1999; Steidle et al., 2016) (Figure 2c). Inositol pyrophosphate molecules may contain up to eight phosphate groups with at least one phosphoanhydride-bonded pyrophosphate moiety, as opposed to the six individually ester-bonded phosphate groups present on $\operatorname{IP}_{6}($ Figure $\mathbf{2 c})$. These results thus indicate that in yeast cells, the presence of inositol pyrophosphates, rather than $\mathrm{IP}_{6}$ itself, may be required for OspB function.

Ddp1p and Siw14p have preferences for the $\beta$-phosphate at the 1- and 5-positions, respectively, and can dephosphorylate 1,5-IP 8 , 1-IP 7 and 5-IP $\mathrm{IP}_{7}$ to produce $\mathrm{IP}_{6}$ (Kilari et al., 2013; Steidle et al., 2016; Wang, Gu, Rolfes, Jessen, \& Shears, 2018) (Figure 2c). A further inositol pyrophosphate species, PP-IP 4 , can be produced from 5-kinase activity on the substrate $\mathrm{IP}_{5}$ (Saiardi, Caffrey, Snyder, \& Shears, 2000). To discriminate whether $\mathrm{PP}-\mathrm{IP}_{4}$ or an $\mathrm{IP}_{6}$-derived inositol pyrophosphate species is involved in OspBmediated growth inhibition, we tested the effect on the OspB phenotype of a deletion in IPKI, which encodes the 2-kinase that generates $\mathrm{IP}_{6}$ from $\mathrm{IP}_{5}$ (York, Odom, Murphy, Ives, \& Wente, 1999). Deletion of IPK1 suppressed OspB-mediated sensitization to caffeine (Figure 2d), demonstrating that the cofactor(s) required for OspB function in yeast cells is specifically one or more inositol pyrophosphate species synthesized from the precursor $\mathrm{IP}_{6}$.

\section{In mammalian cells, OspB activity depends on inositol pyrophosphates}

The inositol phosphate biosynthetic pathway is conserved throughout eukaryotes. However, in mammalian cells, several isoforms exist of the enzymes that carry out each step of the biosynthetic pathway. $\mathrm{IP}_{6}$ and $1-\mathrm{IP}_{7}$ are phosphorylated at the 5-position by $\mathrm{Kcs} 1 \mathrm{p}$ in yeast, whereas in mammalian cells this activity is conducted by isoforms 1,2 and 3 of inositol hexakisphosphate kinase (IP6K1/2/3) 

Vip1p, of which the mammalian homologs are isoforms 1 and 2 of diphosphoinositolpentakisphosphate kinase (PPIP5K1/2) (Choi, Williams, Cho, Falck, \& Shears, 2007; Fridy, Otto, Dollins, \& York, 2007; Mulugu et al., 2007). Biochemical analyses of inositol phosphate levels in mammalian cells reveal that aside from the major species $\mathrm{IP}_{6}, 5-\mathrm{IP}_{7}$ and $1,5-\mathrm{IP}_{8}$ are relatively abundant, whereas $1-\mathrm{IP}_{7}$ constitutes just $2 \%$ of cellular $\mathrm{IP}_{7}(\mathrm{Gu}$, Wilson, Jessen, Saiardi, \& Shears, 2016). Thus, the primary pathway of inositol pyrophosphate synthesis from $\mathrm{IP}_{6}$ is thought to proceed via 5 - $\mathrm{IP}_{7}$ and to be catalyzed by IP6K enzymes.

To determine whether inositol pyrophosphates are required for OspB activity in mammalian cells, we examined OspB during infection with S. flexneri. When Shigella infects cell monolayers, it spreads from cell to cell using actin-based motility, with eventual death of the infected cells (Bernardini, Mounier, D'Hauteville, Coquis-Rondon, \& Sansonetti, 1989; Carneiro et al., 2009). Over the course of 48-72 h of infection, bacterial spread creates central areas of cellular debris, known as plaques. By simultaneously activating mTOR-induced cell proliferation of viable cells at the periphery of the plaques, OspB restricts the total area of plaques formed by S. flexneri in cell monolayers (Lu et al., 2015). Consequently, an $\triangle o s p B$ mutant produces larger plaques than the wild type strain. To test the role of inositol pyrophosphates in OspB activity in mammalian cells, we assessed the impact of the presence or absence of OspB on the area of spread of S. flexneri strains with severely reduced inositol pyrophosphate levels.

Most cellular 5-IP 7 is synthesized by isoform 1 of IP6K (IP6K1), such that in cells with a deletion in IP6K1, levels of inositol pyrophosphates are markedly reduced (Bhandari, Juluri, Resnick, \& Snyder, 2008). A previously described (Lu et al., 2015), in $I P 6 K^{+/+}$cells, wild type $S$. flexneri produced plaques that were significantly smaller than those of the $\triangle o s p B$ mutant (Figures $\mathbf{3 b}$ and $\mathbf{c}$ ). In contrast, in the absence of IP6KI, wild type S. flexneri produced plaques that were significantly larger than those it produced in $I P 6 K I^{+/+}$cells. Moreover, in $I P 6 K 1^{-/-}$cells, the plaques produced by the wild type strain 
pyrophosphates are necessary for the ability of OspB to restrict plaque size, indicating that, as in yeast cells, OspB depends on one or more of these eukaryotic signaling molecules for full activity in mammalian cells.

Whereas $\mathrm{IP}_{7}$ and $\mathrm{IP}_{8}$ species have been shown to be important secondary messengers, influencing the cell cycle, cellular energy levels and vesicle trafficking (Chanduri et al., 2016; Lee, Mulugu, York, \& O'Shea, 2007; Szijgyarto, Garedew, Azevedo, \& Saiardi, 2011), to the best of our knowledge, this is the first demonstration of these molecules being required for bacterial virulence. A described virulenceassociated role for inositol pyrophosphates is in innate immune responses to viral pathogens, whereby production of 1-IP 7 by PPIP5K2 promotes the type I interferon response (Pulloor et al., 2014). By contrast, here we show that the S. flexneri T3SS effector protein co-opts inositol pyrophosphates to facilitate infection, utilizing the host signaling molecule to the advantage of the bacterium.

Given the sequence similarity and predicted structural homology of OspB to the CPDs of TcdA, TcbB and RtxA (Figure 1), and the structural and biochemical evidence that $\mathrm{IP}_{6}$ serves as a cofactor for the cysteine protease domains of these toxins, the mechanism by which inositol pyrophosphates are required for OspB activity is presumably analogous to the role of $\mathrm{IP}_{6}$ in $\mathrm{TcdA}$, TcbB and RtxA, namely as a cofactor. The negatively-charged inositol phosphate cofactor binds to a pocket in these CPDs that consists of several positively-charged residues (predominantly lysines and arginines) and cofactor binding induces a conformational change in the active site, which in turn activates proteolysis (Lupardus, Shen, Bogyo, \& Garcia, 2008; Prochazkova et al., 2009; Prochazkova \& Satchell, 2008; Pruitt et al., 2009; Shen et al., 2011). OspB is also rich in positively-charged residues; the 288-residue protein contains 31 lysines and 8 arginines. However, the sequence of OspB that aligns with RtxA and

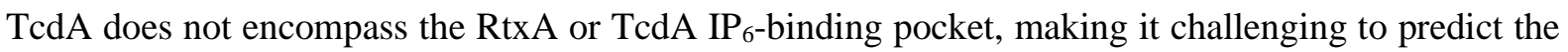
inositol pyrophosphate binding pocket in OspB.

Several bacterial virulence factors, such as the T3SS effectors YopJ of Yersinia spp., IcsB of S. flexneri, and the aforementioned MARTX and clostridial toxins, are activated by $\mathrm{IP}_{6}$ in vitro (Liu et al., 2018; Mittal, Peak-Chew, Sade, Vallis, \& McMahon, 2010; Prochazkova \& Satchell, 2008; Reineke et al., 2007). However, which inositol phosphate species activates these bacterial proteins in situ in the host 
cell cytosol has not been explicitly determined. One report into the activation of TcdB found that in vitro, $\mathrm{IP}_{7}$ induces autoproteolysis more efficiently than $\mathrm{IP}_{6}$ (Savidge et al., 2011), raising the possibility that in vivo, an inositol pyrophosphate may be the preferred cofactor.

We show that the suppression of OspB-mediated yeast growth inhibition in the absence of ipkl indicates that $\mathrm{IP}_{6}, \mathrm{IP}_{7}$ and/or $\mathrm{IP}_{8}$ are needed for OspB activity in yeast. Furthermore, through over-expression of $D D P 1$ or $S I W 14$, which reduces cellular levels of inositol pyrophosphates, we demonstrated that $\mathrm{IP}_{6}$ is unlikely to be the relevant inositol phosphate species activating OspB (Figure 2). VPA1380, the $V$. parahaemolyticus ortholog of OspB, requires IPK1 for its activity, and mutagenesis of predicted $\mathrm{IP}_{6^{-}}$ binding residues abrogated its function (Calder et al., 2014). Since in addition to being unable to produce $\mathrm{IP}_{6}$, an ipk $1 \Delta$ mutant is unable to produce $\mathrm{IP}_{7}$ or $\mathrm{IP}_{8}$, it is plausible that inositol pyrophosphates are the preferred cofactors for activating all members of the OspB family of effector proteins.

With current data, we cannot discriminate which single species or whether multiple species among 1$\mathrm{IP}_{7}, 5-\mathrm{IP}_{7}$ and/or $1,5-\mathrm{IP}_{8}$ is/are functioning as a cofactor of $\mathrm{OspB}$. We also cannot eliminate the possibilities that the biosynthetic enzymes themselves are playing a role or that modulation of inositol pyrophosphates levels has an indirect effect on OspB activity; however, we believe that the preponderance of evidence weighs in favor of a physical association between OspB and inositol pyrophosphates. It is apparent that cofactor promiscuity exists in vitro and that the relative concentrations of inositol phosphates species and sub-cellular localization and sequestration in cells will be important determinants in cofactor preference. In conclusion, we present the first demonstration of the exploitation of the host inositol pyrophosphates by a bacterial virulence factor in vivo, furthering our understanding of the utilization of host cofactors by pathogens during infection. 


\section{Experimental Procedures}

\section{Growth conditions and cell culture}

S. flexneri serotype 2a wild type strain $2457 \mathrm{~T}$ and its isogenic ospB mutant have been described (Labrec, Schneider, Magnani, \& Formal, 1964; Lu et al., 2015). Bacteria were isolated from single red colonies on agar containing Congo red and were grown in tryptic soy broth at $37{ }^{\circ} \mathrm{C}$ with agitation. E. coli DH10B (Grant, Jessee, Bloom, \& Hanahan, 1990) was used as the routine cloning host and was grown in Luria broth at $37^{\circ} \mathrm{C}$. S. cerevisiae $\mathrm{S} 288 \mathrm{C}$ was used as the heterologous expression host to probe the roles of host proteins in the function of $\mathrm{OspB}$ and was routinely cultured at $30{ }^{\circ} \mathrm{C}$ in yeast extractpeptone-dextrose (YPD) broth or in synthetic selective media (MP Biomedicals) lacking histidine, uracil and/or leucine for auxotrophic selection. $1.5 \%(\mathrm{w} / \mathrm{v})$ agar was added for solid media formulations, and where appropriate, media was supplemented with $50 \mu \mathrm{g} / \mathrm{ml}$ ampicillin, $2 \%$ (w/v) Dglucose, $2 \%(\mathrm{w} / \mathrm{v})$ D-galactose, $6 \mathrm{mM}$ caffeine or $5 \mathrm{nM}$ rapamycin.

$I P 6 K 1^{+/+}$and $I P 6 K 1^{-/-}$mouse embryonic fibroblast cell lines (provided by Dr Anutosh Chakraborty, St (Gibco) supplemented with $10 \%$ (v/v) fetal bovine serum (FBS) at $37{ }^{\circ} \mathrm{C}$ with $5 \% \mathrm{CO}_{2}$. Inhibition of mTOR was achieved through the addition of $10 \mathrm{nM}$ rapamycin to mammalian cell culture media.

\section{Bioinformatic analyses}

In silico modelling of the tertiary structure of OspB was conducted on the Phyre2 server (Kelley, Mezulis, Yates, Wass, \& Sternberg, 2015), whereas alignment with the crystal structures of RtxA ${ }^{\mathrm{vC}}$ (Lupardus et al., 2008) and TcdA (Pruitt et al., 2009) was achieved using the CEAlign algorithm within PyMol (Schrödinger, LLC). Protein sequences were retrieved from the non-redundant NCBI database and aligned using MUSCLE (Edgar, 2004) before manual curation to select the regions of interest.

\section{Genetic manipulations}

For expression of $\operatorname{spB}$ in $S$. cerevisiae, the $\operatorname{sp} B$ gene from S. flexneri $2457 \mathrm{~T}$ was cloned into the 
the EGFP gene. Generation of OspB point mutants was achieved by splicing by overlap extension PCR using the following combinations of primers:

\section{CCGTTTTACTTCAAGCGGCTCCGCTGATAAAGTGG and}

CCACTTTATCAGCGGAGCCGCTTGAAGTAAAACGG for C184S;

5'-GGTTTATATTCTTGGGGCCGGTAGTCCTGGTTCTCATC and

5'-GATGAGAACCAGGACTACCGGCCCCAAGAATATAAACC for H144A;

\section{5'- TAGTAATAAATAATGCTGATGACGCAT and}

5'- ATGCGTCATCAGCATTATTTATTACTA for D108A. Allelic exchange was used to construct the ipk1 1 mutant in S. cerevisiae BY4741, replacing the gene with a LEU2 cassette. The LEU2 gene was amplified by PCR from the pRS315 vector using primers

\section{5'-ACCAGTCGAAAATTGTCAGAGATAAGTTCCTTTTTTGAAAAGAAAGATCGTAACTGTG} GGAATACTCAGG and

\section{5'-TAATGTATGTGCATCTGCCAGTACCAAAGGTGGAAAGAAAAGTATACAGTTTTAAGCA}

AGGATTTTC. The resulting product was transformed into BY4741, and to select for homologous recombination, the yeast were grown on selective media. Successful integration into the ipkl locus was assessed by colony PCR using primers 5'-CACGTAGGAAAGCGA and 5'-CCCTTCGTTGAATATCG and by demonstration of loss of leucine auxotrophy. Yeast were transformed using the lithium acetate method.

\section{Yeast growth assays and screen for suppressors of growth inhibition}

Individual yeast transformants that constitutively express $\operatorname{sp} B$ or derivatives containing point mutations were grown in synthetic selective liquid media containing $2 \% \mathrm{D}$-glucose. To investigate the impact of OspB constructs on growth, yeast cells were washed and serially diluted four-fold in phosphate-buffered saline before $5 \mu 1$ of each dilution were spotted on synthetic selective solid media. Media contained 2\% D-glucose either without further additives or supplemented with $6 \mathrm{mM}$ caffeine or $5 \mathrm{nM}$ rapamycin. The role of the yeast $I P K 1$ gene was assessed similarly.

To screen for suppressors of OspB-mediated toxicity in S. cerevisiae by yeast gene over-expression, the strain BY4742 pAG413GPD-ospB was mated with the haploid GST-fusion yeast over-expression 
library (YSC4423, Dharmacon) on YPD. The resulting diploids were selected by plating on noninducing synthetic selective media containing $2 \% \mathrm{D}$-glucose. The screen was conducted by spotting in quadruplicate on inducing synthetic selective solid media containing 2\% D-galactose and $6 \mathrm{mM}$ caffeine. All steps in the screen were conducted in an automated manner as described previously (Slagowski et al., 2008). Suppressors were classified as strains which displayed qualitatively moderate to robust growth of all four spots on the caffeine plate four days after pinning. Direct analysis of suppressor genes $D D P 1$ and SIW14 was achieved through plasmid isolation and transformation into BY4741 pAG413GPD-ospB and assayed as above by serial dilution onto media containing D-galactose.

\section{Transfection}

Transfection plasmids were constructed by cloning the $o s p B$ gene into the pCMV-myc vector at EcoRI and XhoI sites. A construct encoding OspB or its $\mathrm{C} 184 \mathrm{~S}$ derivative was also amplified with a C-terminal triple FLAG and hexahistidine tag and cloned into pcDNA3 at BamHI and XhoI sites. Cells were transfected with plasmids using FuGENE 6 (Promega) according to the manufacturer's instructions, and experimental samples were analyzed $24 \mathrm{~h}$ after transfection.

\section{SDS-PAGE and immunoblotting}

For immunoblot analysis, protein samples were separated by SDS-PAGE, transferred to nitrocellulose membranes and detected by western blot analysis using standard procedures. The antibodies used were peroxidase-conjugated anti- $\beta$-actin (A3854, Sigma; diluted to 1:10 000), anti- $\alpha$-tubulin (sc-53030, Santa Cruz; diluted to 1:1000), anti-FLAG (F3165, Sigma; diluted to 1:1000), anti-myc (631206,

280 Clontech; diluted to 1:1000) and anti-OspB (diluted to 1:10 000). The rabbit anti-OspB antibody was generated (Covance Inc.) against a 14-mer peptide of OspB located 18 residues from the C-terminus.

\section{Plaque assays}

Mouse embryonic fibroblasts were seeded in 6-well plates and infected with exponential phase $S$. flexneri strains at a multiplicity of infection of 0.004 . Bacteria were centrifuged onto the cells at $830 \mathrm{~g}$ for $10 \mathrm{~min}$ before incubation for $50 \mathrm{~min}$ at $37{ }^{\circ} \mathrm{C}$ in $5 \% \mathrm{CO}_{2}$. The media was replaced with a $0.5 \%(\mathrm{w} / \mathrm{v})$ 
bioRxiv preprint doi: https://doi.org/10.1101/2021.09.01.458261; this version posted September 1 , 2021. The copyright holder for this preprint (which was not certified by peer review) is the author/funder, who has granted bioRxiv a license to display the preprint in perpetuity. It is made available under aCC-BY 4.0 International license. adding a $0.7 \%(w / v)$ agarose overlay in DMEM containing FBS, gentamicin and $0.002 \%(w / v)$ neutral

289 red dye. Infected monolayers were imaged using a scanner after a further 150 min incubation. Semi-

290 automated measurement of plaque area was conducted using FIJI (Schindelin et al., 2012) using a script

291 developed in-house. Statistically significant differences in plaque size was determined with the tests described in the figure legend using Prism 8.0 (GraphPad). 


\section{Acknowledgements}

294 We thank Austin C. Hachey and Yang Fu for technical assistance. We are grateful to Dr. Anutosh

295 Chakraborty (St Louis University, St Louis, MO) and Prof. Solomon H. Snyder (Johns Hopkins Medical

296 School, Baltimore, MD) for the gift of $I P 6 K 1^{-1-}$ mouse embryonic fibroblasts. We thank Stephen B.

297 Shears, Henning Jessen, and D. Borden Lacy for helpful discussions. This research was supported by

298 Department of Defense grant TS160046 (to M.B.G.), funding from the Massachusetts General Hospital

299 Executive Committee on Research (to M.B.G.), NIH grants T32 AI007061 and F32 AI131582 (to

300 H.D.E.) and R01 AI064285 (to C.F.L.). The authors have no conflicts of interest. 


\section{References}

302

Agaisse, H. (2016). Molecular and Cellular Mechanisms of Shigella flexneri Dissemination. Frontiers in Cellular and Infection Microbiology, 6(March), 29. http://doi.org/10.3389/fcimb.2016.00029

Ambrosi, C., Pompili, M., Scribano, D., Limongi, D., Petrucca, A., Cannavacciuolo, S., ... Nicoletti, M. (2015). The Shigella flexneri OspB effector: an early immunomodulator. International Journal of Medical Microbiology, 305(1), 75-84. http://doi.org/10.1016/j.ijmm.2014.11.004

Bernardini, M. L., Mounier, J., D’Hauteville, H., Coquis-Rondon, M., \& Sansonetti, P. J. (1989). Identification of icsA, a plasmid locus of Shigella flexneri that governs bacterial intra- and intercellular spread through interaction with F-actin. Proceedings of the National Academy of Sciences of the United States of America, 86(10), 3867-71. http://doi.org/10.1073/pnas.86.10.3867

Bhandari, R., Juluri, K. R., Resnick, A. C., \& Snyder, S. H. (2008). Gene deletion of inositol hexakisphosphate kinase 1 reveals inositol pyrophosphate regulation of insulin secretion, growth, and spermiogenesis. Proceedings of the National Academy of Sciences of the United States of America, 105(7), 2349-53. http://doi.org/10.1073/pnas.0712227105

Calder, T., Kinch, L. N., Fernandez, J., Salomon, D., Grishin, N. V., \& Orth, K. (2014). Vibrio type III effector VPA1380 is related to the cysteine protease domain of large bacterial toxins. PLoS ONE, 9(8), e104387. http://doi.org/10.1371/journal.pone.0104387

Carayol, N., \& Tran Van Nhieu, G. (2013). The inside story of Shigella invasion of intestinal epithelial cells. Cold Spring Harbor Perspectives in Medicine, 3(10), a016717. http://doi.org/10.1101/cshperspect.a016717

Carneiro, L. A. M., Travassos, L. H., Soares, F., Tattoli, I., Magalhaes, J. G., Bozza, M. T., ... Girardin, S. E. (2009). Shigella induces mitochondrial dysfunction and cell death in nonmyleoid cells. Cell Host and Microbe, 5(2), 123-36. http://doi.org/10.1016/j.chom.2008.12.011 
hexakisphosphate kinase 1 (IP6K1) activity is required for cytoplasmic dynein-driven transport. The Biochemical Journal, 473(19), 3031-47. http://doi.org/10.1042/BCJ20160610

Cherry, J. M., Hong, E. L., Amundsen, C., Balakrishnan, R., Binkley, G., Chan, E. T., ... Wong, E. D. (2012). Saccharomyces Genome Database: the genomics resource of budding yeast. Nucleic Acids Research, 40(Database issue), D700-5. http://doi.org/10.1093/nar/gkr1029

Choi, J. H., Williams, J., Cho, J., Falck, J. R., \& Shears, S. B. (2007). Purification, sequencing, and molecular identification of a mammalian PP-InsP $\mathrm{P}_{5}$ kinase that is activated when cells are exposed to hyperosmotic stress. The Journal of Biological Chemistry, 282(42), 30763-75. http://doi.org/10.1074/jbc.M704655200

Edgar, R. C. (2004). MUSCLE: multiple sequence alignment with high accuracy and high throughput. Nucleic Acids Research, 32(5), 1792-7. http://doi.org/10.1093/nar/gkh340

Egerer, M., Giesemann, T., Jank, T., Satchell, K. J. F., \& Aktories, K. (2007). Auto-catalytic cleavage of Clostridium difficile toxins A and B depends on cysteine protease activity. The Journal of Biological Chemistry, 282(35), 25314-21. http://doi.org/10.1074/jbc.M703062200

Fridy, P. C., Otto, J. C., Dollins, D. E., \& York, J. D. (2007). Cloning and characterization of two human VIP1-like inositol hexakisphosphate and diphosphoinositol pentakisphosphate kinases. The Journal of Biological Chemistry, 282(42), 30754-62. http://doi.org/10.1074/jbc.M704656200

Fukazawa, A., Alonso, C., Kurachi, K., Gupta, S., Lesser, C. F., McCormick, B. A., \& Reinecker, H.C. (2008). GEF-H1 mediated control of NOD1 dependent NF-אB activation by Shigella effectors. PLoS Pathogens, 4(11), e1000228. http://doi.org/10.1371/journal.ppat.1000228

Fullner, K. J., \& Mekalanos, J. J. (2000). In vivo covalent cross-linking of cellular actin by the Vibrio cholerae RTX toxin. The EMBO Journal, 19(20), 5315-23. http://doi.org/10.1093/emboj/19.20.5315

Grant, S. G. N., Jessee, J., Bloom, F. R., \& Hanahan, D. (1990). Differential plasmid rescue from 
transgenic mouse DNAs into Escherichia coli methylation-restriction mutants. Proceedings of the National Academy of Sciences of the United States of America, 87(12), 4645-9. Retrieved from http://www.ncbi.nlm.nih.gov/pubmed/2162051

Gu, C., Wilson, M. S. C., Jessen, H. J., Saiardi, A., \& Shears, S. B. (2016). Inositol Pyrophosphate Profiling of Two HCT116 Cell Lines Uncovers Variation in InsP $\mathrm{P}_{8}$ Levels. PloS ONE, 11(10), e0165286. http://doi.org/10.1371/journal.pone.0165286

Just, I., Selzer, J., Wilm, M., von Eichel-Streiber, C., Mann, M., \& Aktories, K. (1995). Glucosylation of Rho proteins by Clostridium difficile toxin B. Nature, 375(6531), 500-3. http://doi.org/10.1038/375500a0

Kelley, L. A., Mezulis, S., Yates, C. M., Wass, M. N., \& Sternberg, M. J. E. (2015). The Phyre2 web portal for protein modeling, prediction and analysis. Nature Protocols, 10(6), 845-858. http://doi.org/10.1038/nprot.2015-053

Khalil, I. A., Troeger, C., Blacker, B. F., Rao, P. C., Brown, A., Atherly, D. E., ... Reiner, R. C. (2018). Morbidity and mortality due to Shigella and enterotoxigenic Escherichia coli diarrhoea: the Global Burden of Disease Study 1990-2016. The Lancet Infectious Diseases, 18(11), 12291240. http://doi.org/10.1016/S1473-3099(18)30475-4

Kilari, R. S., Weaver, J. D., Shears, S. B., \& Safrany, S. T. (2013). Understanding inositol pyrophosphate metabolism and function: kinetic characterization of the DIPPs. FEBS Letters, 587(21), 3464-70. http://doi.org/10.1016/j.febslet.2013.08.035

Labrec, E. H., Schneider, H., Magnani, T. J., \& Formal, S. B. (1964). Epithlelial cell penetration as an essential step in the pathogenesis of bacillary dysentery. Journal of Bacteriology, 88(5), 150318. Retrieved from http://www.ncbi.nlm.nih.gov/pubmed/16562000

Lee, Y.-S., Mulugu, S., York, J. D., \& O’Shea, E. K. (2007). Regulation of a cyclin-CDK-CDK inhibitor complex by inositol pyrophosphates. Science, 316(5821), 109-12. http://doi.org/10.1126/science.1139080 
Liu, W., Zhou, Y., Peng, T., Zhou, P., Ding, X., Li, Z., ... Shao, F. (2018). $N^{\varepsilon}$-fatty acylation of multiple membrane-associated proteins by Shigella IcsB effector to modulate host function. Nature Microbiology, 3(9), 996-1009. http://doi.org/10.1038/s41564-018-0215-6

Lu, R., Herrera, B. B., Eshleman, H. D., Fu, Y., Bloom, A., Li, Z., ... Goldberg, M. B. (2015). Shigella Effector OspB Activates mTORC1 in a Manner That Depends on IQGAP1 and Promotes Cell Proliferation. PLoS Pathogens, 11(10), e1005200. http://doi.org/10.1371/journal.ppat.1005200

Lupardus, P. J., Shen, A., Bogyo, M., \& Garcia, K. C. (2008). Small molecule-induced allosteric activation of the Vibrio cholerae RTX cysteine protease domain. Science, 322(5899), 265-8. http://doi.org/10.1126/science.1162403

Mittal, R., Peak-Chew, S. Y., Sade, R. S., Vallis, Y., \& McMahon, H. T. (2010). The acetyltransferase activity of the bacterial toxin YopJ of Yersinia is activated by eukaryotic host cell inositol hexakisphosphate. The Journal of Biological Chemistry, 285(26), 19927-34. http://doi.org/10.1074/jbc.M110.126581

Mulugu, S., Bai, W., Fridy, P. C., Bastidas, R. J., Otto, J. C., Dollins, D. E., .. York, J. D. (2007). A conserved family of enzymes that phosphorylate inositol hexakisphosphate. Science, 316(5821), 106-9. http://doi.org/10.1126/science.1139099

Prochazkova, K., \& Satchell, K. J. F. (2008). Structure-function analysis of inositol hexakisphosphate-induced autoprocessing of the Vibrio cholerae multifunctional autoprocessing RTX toxin. The Journal of Biological Chemistry, 283(35), 23656-64. http://doi.org/10.1074/jbc.M803334200

Prochazkova, K., Shuvalova, L. A., Minasov, G., Voburka, Z., Anderson, W. F., \& Satchell, K. J. F. (2009). Structural and molecular mechanism for autoprocessing of MARTX toxin of Vibrio cholerae at multiple sites. The Journal of Biological Chemistry, 284(39), 26557-68. http://doi.org/10.1074/jbc.M109.025510 
Pruitt, R. N., Chagot, B., Cover, M., Chazin, W. J., Spiller, B., \& Lacy, D. B. (2009). Structurefunction analysis of inositol hexakisphosphate-induced autoprocessing in Clostridium difficile toxin A. The Journal of Biological Chemistry, 284(33), 21934-40. http://doi.org/10.1074/jbc.M109.018929

Pulloor, N. K., Nair, S., McCaffrey, K., Kostic, A. D., Bist, P., Weaver, J. D., ... Krishnan, M. N. (2014). Human genome-wide RNAi screen identifies an essential role for inositol pyrophosphates in Type-I interferon response. PLoS Pathogens, 10(2), e1003981. http://doi.org/10.1371/journal.ppat.1003981

Reineke, J., Tenzer, S., Rupnik, M., Koschinski, A., Hasselmayer, O., Schrattenholz, A., ... von Eichel-Streiber, C. (2007). Autocatalytic cleavage of Clostridium difficile toxin B. Nature, 446(7134), 415-9. http://doi.org/10.1038/nature05622

Reinke, A., Chen, J. C.-Y., Aronova, S., \& Powers, T. (2006). Caffeine targets TOR complex I and provides evidence for a regulatory link between the FRB and kinase domains of Tor1p. The Journal of Biological Chemistry, 281(42), 31616-26. http://doi.org/10.1074/jbc.M603107200

Safrany, S. T., Ingram, S. W., Cartwright, J. L., Falck, J. R., McLennan, A. G., Barnes, L. D., \& Shears, S. B. (1999). The diadenosine hexaphosphate hydrolases from Schizosaccharomyces pombe and Saccharomyces cerevisiae are homologues of the human diphosphoinositol polyphosphate phosphohydrolase. The Journal of Biological Chemistry, 274(31), 21735-40. http://doi.org/10.1074/jbc.274.31.21735

Saiardi, A., Caffrey, J. J., Snyder, S. H., \& Shears, S. B. (2000). The inositol hexakisphosphate kinase family. Catalytic flexibility and function in yeast vacuole biogenesis. The Journal of Biological Chemistry, 275(32), 24686-92. http://doi.org/10.1074/jbc.M002750200

Saiardi, A., Erdjument-Bromage, H., Snowman, A. M., Tempst, P., \& Snyder, S. H. (1999). Synthesis of diphosphoinositol pentakisphosphate by a newly identified family of higher inositol polyphosphate kinases. Current Biology, 9(22), 1323-6. http://doi.org/10.1016/s09609822(00)80055-x 
Savidge, T. C., Urvil, P., Oezguen, N., Ali, K., Choudhury, A., Acharya, V., ... Pothoulakis, C. (2011). Host $S$-nitrosylation inhibits clostridial small molecule-activated glucosylating toxins. Nature Medicine, 17(9), 1136-41. http://doi.org/10.1038/nm.2405

Schindelin, J., Arganda-Carreras, I., Frise, E., Kaynig, V., Longair, M., Pietzsch, T., ... Cardona, A. (2012). Fiji: an open-source platform for biological-image analysis. Nature Methods, 9(7), 67682. http://doi.org/10.1038/nmeth.2019

Sheahan, K., Cordero, C. L., \& Satchell, K. J. F. (2007). Autoprocessing of the Vibrio cholerae RTX toxin by the cysteine protease domain. The EMBO Journal, 26(10), 2552-61. http://doi.org/10.1038/sj.emboj.7601700

Shears, S. B. (2018). Intimate connections: Inositol pyrophosphates at the interface of metabolic regulation and cell signaling. Journal of Cellular Physiology, 233(3), 1897-1912. http://doi.org/10.1002/jcp.26017

Shen, A., Lupardus, P. J., Gersch, M. M., Puri, A. W., Albrow, V. E., Garcia, K. C., \& Bogyo, M. (2011). Defining an allosteric circuit in the cysteine protease domain of Clostridium difficile toxins. Nature Structural \& Molecular Biology, 18(3), 364-71. http://doi.org/10.1038/nsmb.1990

Slagowski, N. L., Kramer, R. W., Morrison, M. F., LaBaer, J., \& Lesser, C. F. (2008). A functional genomic yeast screen to identify pathogenic bacterial proteins. PLoS Pathogens, 4(1), e9. http://doi.org/10.1371/journal.ppat.0040009

Sopko, R., Huang, D., Preston, N., Chua, G., Papp, B., Kafadar, K., ... Andrews, B. (2006). Mapping pathways and phenotypes by systematic gene overexpression. Molecular Cell, 21(3), 319-30. http://doi.org/10.1016/j.molcel.2005.12.011

Steidle, E. A., Chong, L. S., Wu, M., Crooke, E., Fiedler, D., Resnick, A. C., \& Rolfes, R. J. (2016). A novel inositol pyrophosphate phosphatase in Saccharomyces cerevisiae: Siw14 protein selectively cleaves the $\beta$-phosphate from 5-diphosphoinositol pentakisphosphate (5PP-IP $)$. The 
bioRxiv preprint doi: https://doi org/10.1101/2021.09.01.458261; this version posted September 1, 2021. The copyright holder for this preprint (which was not certified by peer review) is the author/funder, who has granted bioRxiv a license to display the preprint in perpetuity. It is made available under aCC-BY 4.0 International license.

Szijgyarto, Z., Garedew, A., Azevedo, C., \& Saiardi, A. (2011). Influence of inositol pyrophosphates on cellular energy dynamics. Science, 334(6057), 802-5. http://doi.org/10.1126/science.1211908

Wang, H., Gu, C., Rolfes, R. J., Jessen, H. J., \& Shears, S. B. (2018). Structural and biochemical characterization of Siw14: A protein-tyrosine phosphatase fold that metabolizes inositol pyrophosphates. The Journal of Biological Chemistry, 293(18), 6905-6914. http://doi.org/10.1074/jbc.RA117.001670 dependent inositol polyphosphate kinase pathway required for efficient messenger RNA export. Science, 285(5424), 96-100. Retrieved from http://www.ncbi.nlm.nih.gov/pubmed/10390371 flexneri type III secretion system effectors OspB and OspF target the nucleus to downregulate the host inflammatory response via interactions with retinoblastoma protein. Molecular Microbiology, 71(2), 350-68. http://doi.org/10.1111/j.1365-2958.2008.06524.x 
bioRxiv preprint doi: https://doi.org/10.1101/2021.09.01.458261; this version posted September 1, 2021. The copyright holder for this preprint (which was not certified by peer review) is the author/funder, who has granted bioRxiv a license to display the preprint in perpetuity. It is made available under aCC-BY 4.0 International license.

(a)

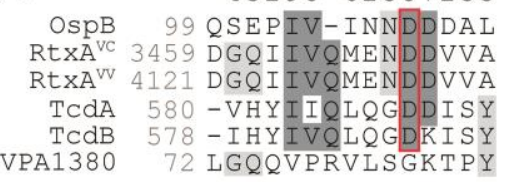

$6496787 * * * 55--256$

$596877 * 7567---533$

OSPB 178 DIRFTSCGSAD---KVA

RtXA ${ }^{\text {VC }} 3562$ HIS IVGCS LVS- - - DDK

RtXAV $^{\mathrm{VV}} 4224 \mathrm{HISIVGCSLVS---DDK}$

TCDA 694 EVNLLGCNMFSYDFNVE

TCdB 692 EINLLGCNMFSYSINVE

VPA1380 189 DIRLTCCNSAD---KRE

(c)

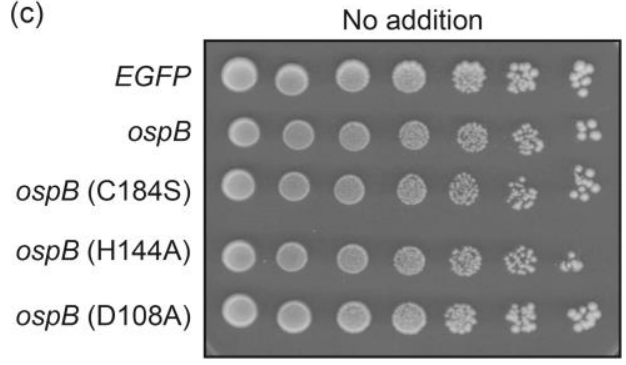

(b)

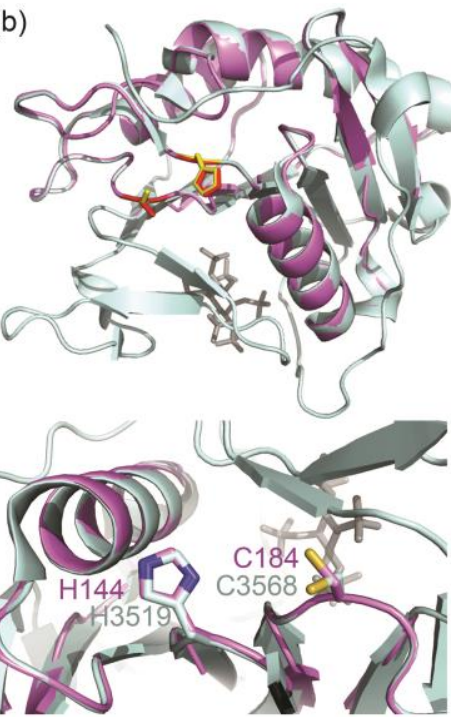

Caffeine

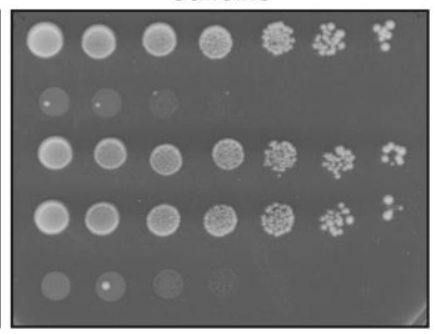

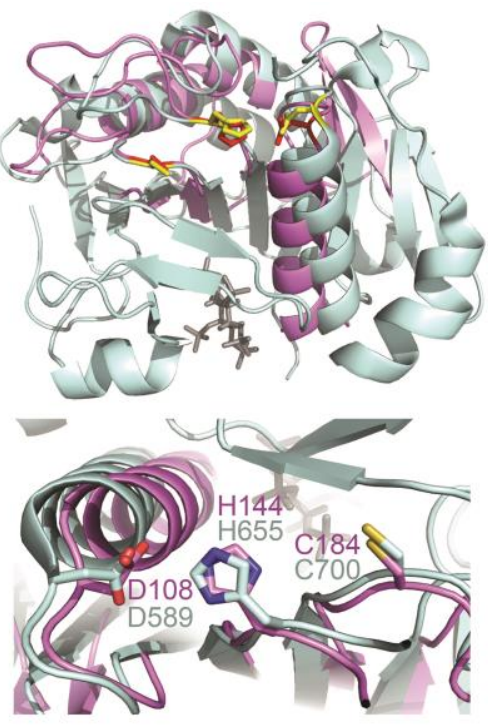

Rapamycin

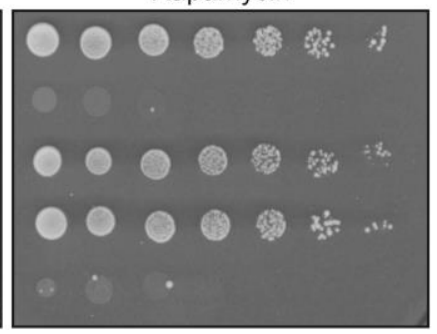

Figure 1: Prediction of catalytic residues of OspB. (a) Multiple sequence alignment of OspB with the catalytic residues of the cysteine protease domains of RtxA from $V$. cholerae ( $\operatorname{RtxA}^{\mathrm{VC}}$ ) and $V$. vulnificus (RtxA ${ }^{\mathrm{Vv}}$ ), C. difficile TcdA and TcdB, and the OspB ortholog VPA1380 from V. parahaemolyticus. Red boxes indicate catalytic residues of the cysteine protease domains and the aligned putative catalytic residues of OspB. Darkness of gray shading reflects the conservation of individual residues, and the numbers above the alignment score the conservation at each position. Asterisks denote full conservation among the aligned sequences. (b) Cartoon depictions of a tertiary structure model of OspB (violet) on the CPDs of RtxA ${ }^{\mathrm{VC}}$ (left panels; PDB: 3EEB) and TcdA (right panels; PDB: 3HO6) (pale cyan). In the top panels, the catalytic residues of the cysteine protease

477 domains are denoted by yellow sticks, with the putative catalytic residues of OspB shown as red sticks. $\mathrm{IP}_{6}$ in the RtxA ${ }^{\mathrm{VC}}$ and $\mathrm{TcdB}$ cysteine protease domain structures is shown in dark gray. Enlarged and rotated views show the active sites (bottom panels), highlighting the superposition of the putative OspB catalytic residues with those of the cysteine protease domains, labelled according to the color of the 
bioRxiv preprint doi: https://doi.org/10.1101/2021.09.01.458261; this version posted September 1, 2021. The copyright holder for this preprint (which was not certified by peer review) is the author/funder, who has granted bioRxiv a license to display the preprint in perpetuity. It is made available under aCC-BY 4.0 International license. were spotted on media either without additives or supplemented with the TOR inhibitors caffeine

$483(6 \mathrm{mM})$ or rapamycin $(5 \mathrm{nM})$. Images are representative of three independent replicates. 
bioRxiv preprint doi: https://doi.org/10.1101/2021.09.01.458261; this version posted September 1, 2021. The copyright holder for this preprint (which was not certified by peer review) is the author/funder, who has granted bioRxiv a license to display the preprint in perpetuity. It is made available under aCC-BY 4.0 International license.

(a)

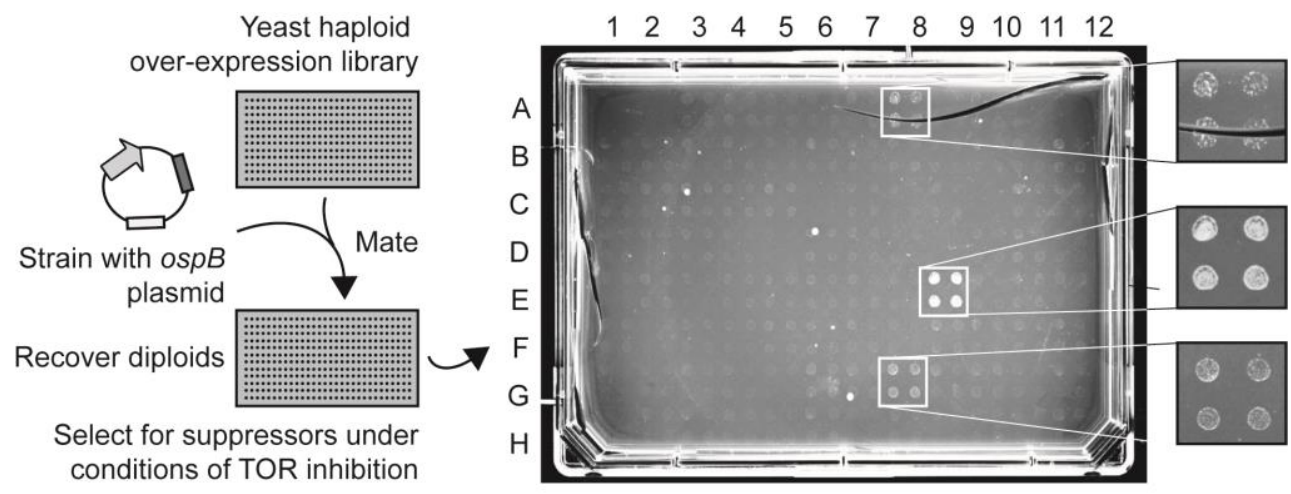

(b)

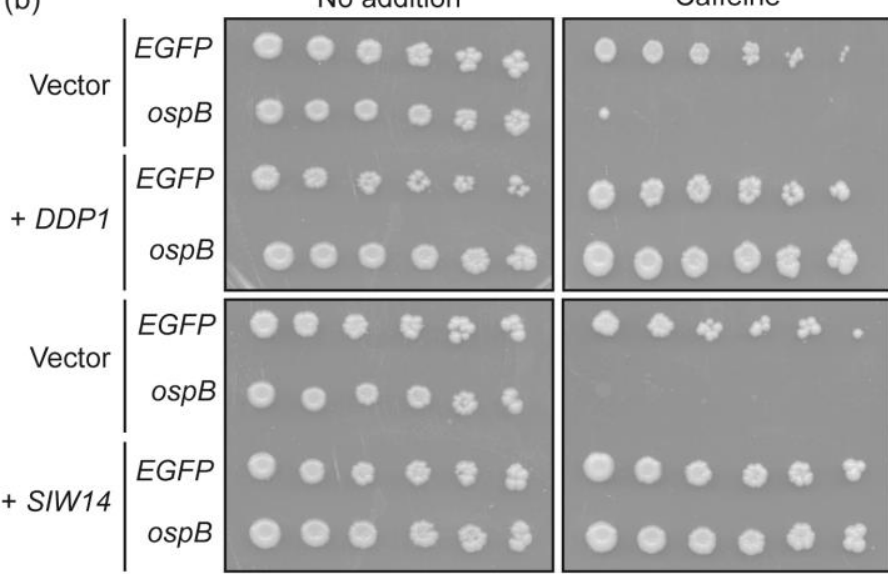

(d)
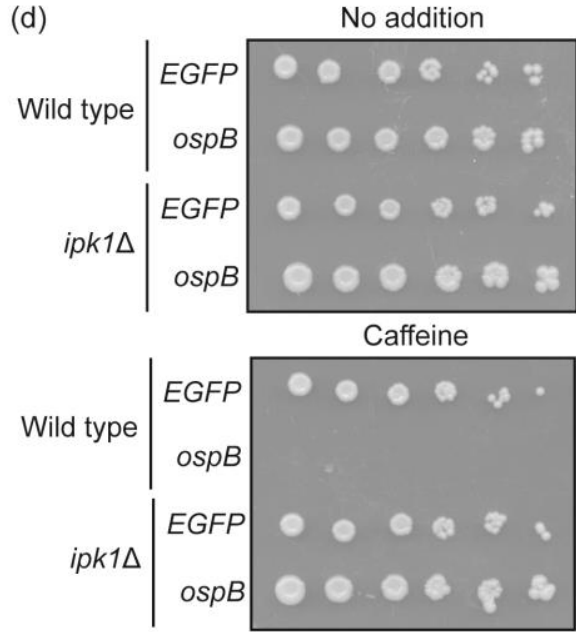

(c)

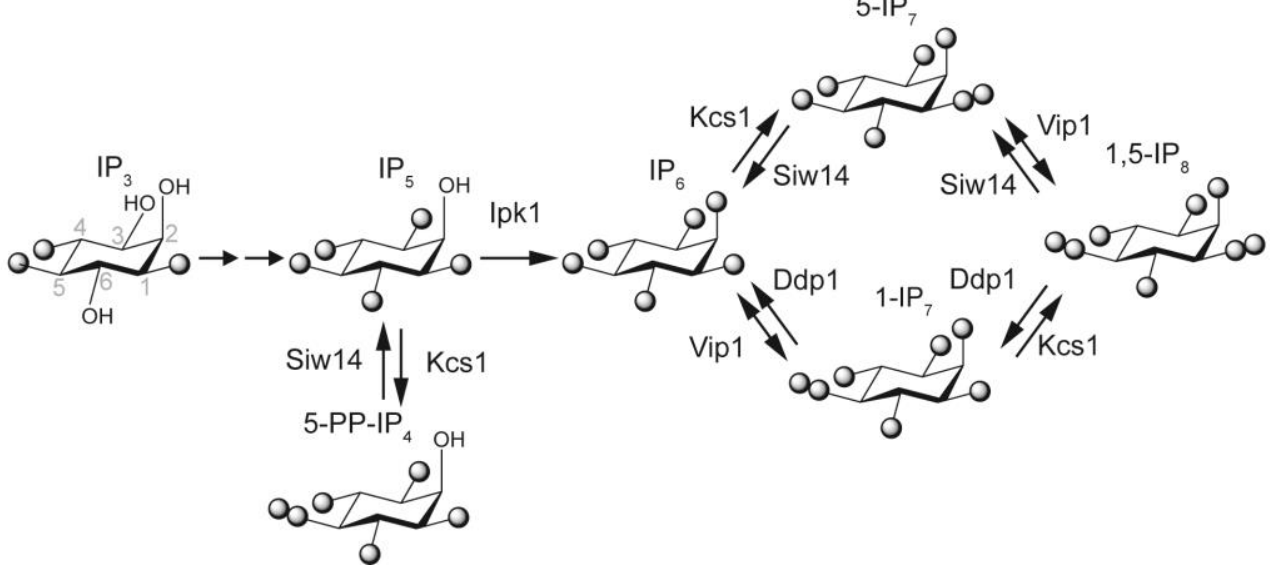

Figure 2: A yeast suppressor screen reveals a role of inositol pyrophosphates in OspB activity. (a)

Schematic of the over-expression library screen designed to identify suppressors of OspB-mediated growth inhibition in the presence of caffeine (See Experimental Procedures for details). An example of a quad-spotted output plate is shown, with three hits magnified. (b) Impact of multi-copy overexpression of $D D P 1$ or $S I W 14$ on growth of yeast strains that express $o s p B$ or an EGFP control. Serial dilutions were spotted in the presence or absence of the TOR inhibitor caffeine. Images are 
representative of four independent replicates. (c) Schematic of the yeast soluble inositol phosphate

492 biosynthetic pathway, with the kinase and phosphatase that catalyze each step indicated (dark gray

493 lettering). The species names are shown in bold lettering. (d) Impact of deletion of ipkl on growth of

494 yeast strains that express $o s p B$ or an EGFP control. Serial dilutions were spotted on media with or

495 without caffeine. Images are representative of four independent replicates. 
(a)

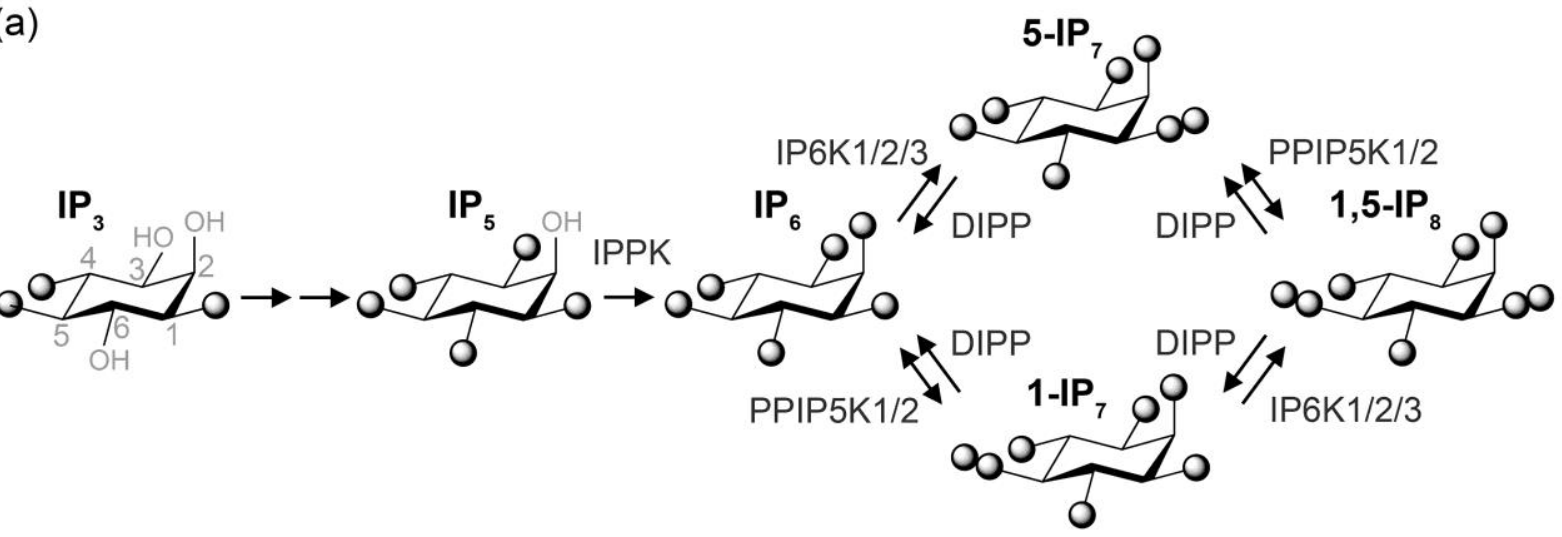

(b)

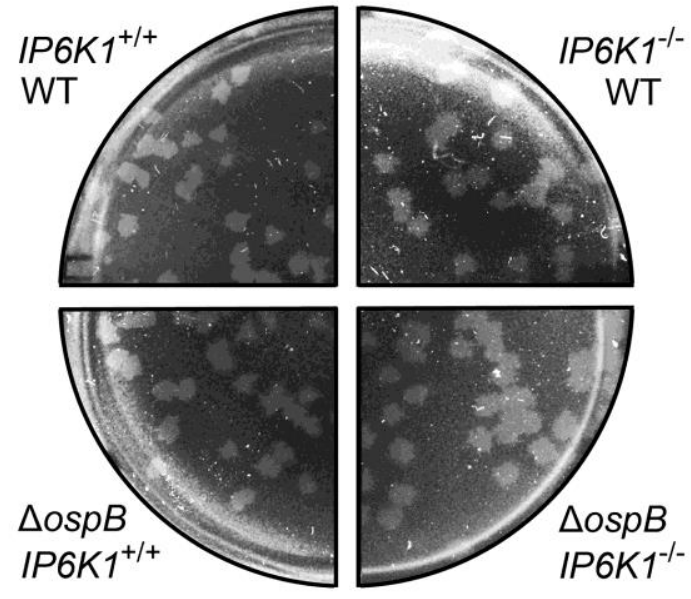

(c)

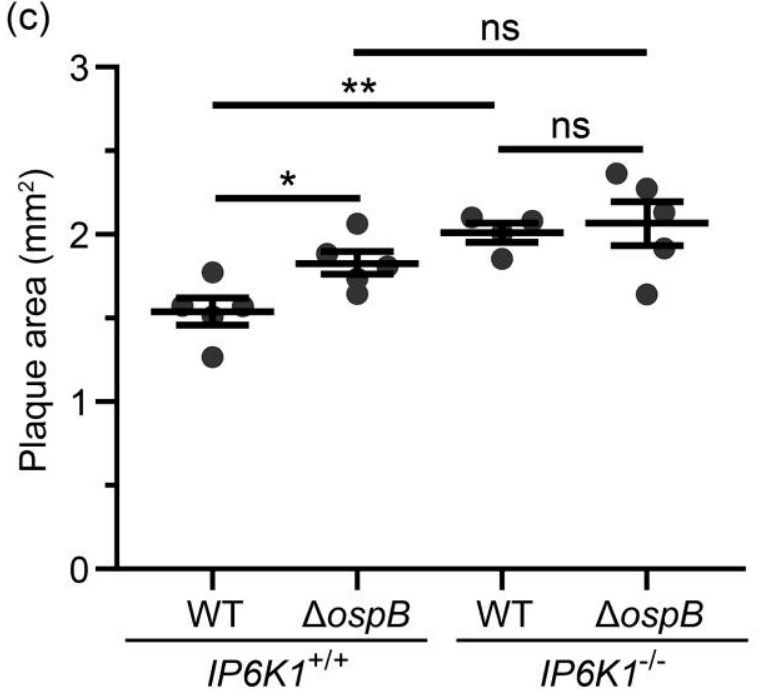
isoforms of enzymes are present at many positions in the pathway (dark gray lettering). Of note, it is thought that the generation of $1,5-\mathrm{IP}_{8}$ from $\mathrm{IP}_{6}$ primarily proceeds via $5-\mathrm{IP}_{7}$, whereas most $1-\mathrm{IP}_{7}$ is thought to be synthesized from 1,5-IP 8 (Gu et al., 2016). The species names are shown in bold lettering. (b-c) Impact of deletion of IP6KI on S. flexneri spread through cell monolayers. Infection of IP6KIdeficient mouse embryonic fibroblasts and littermate-derived wild type control cells with wild type plaque area (c). Data are from at least 4 independent experiments. Two-tailed Student's $t$-test: $* p<$ 
(a)

ospB-

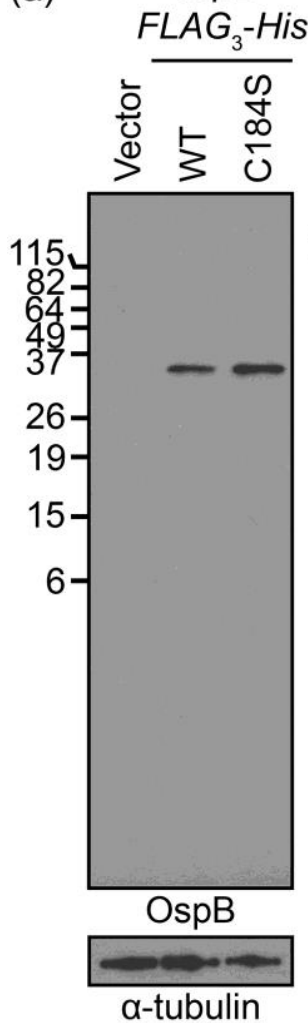

ospB-
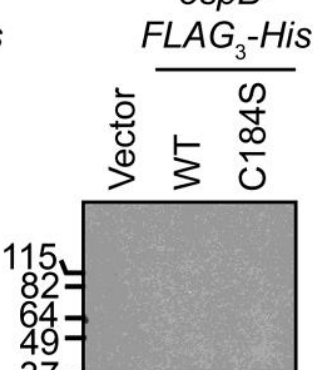

509

510

511

512

513

514

515

516

517 bands from a single blot. (b)

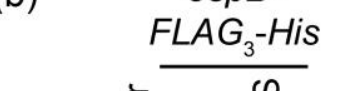

ospB-

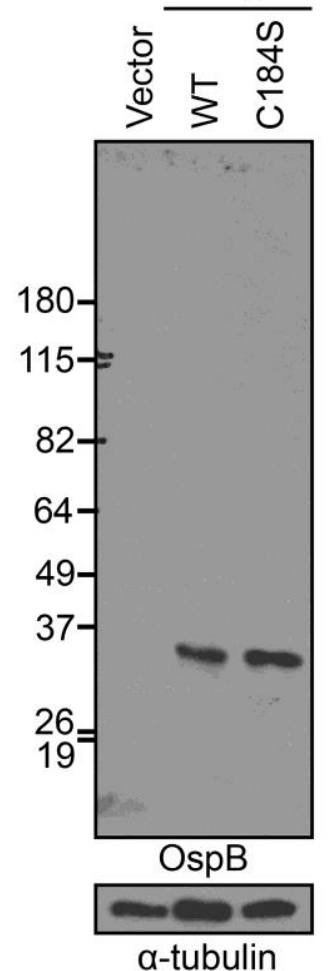

ospB-

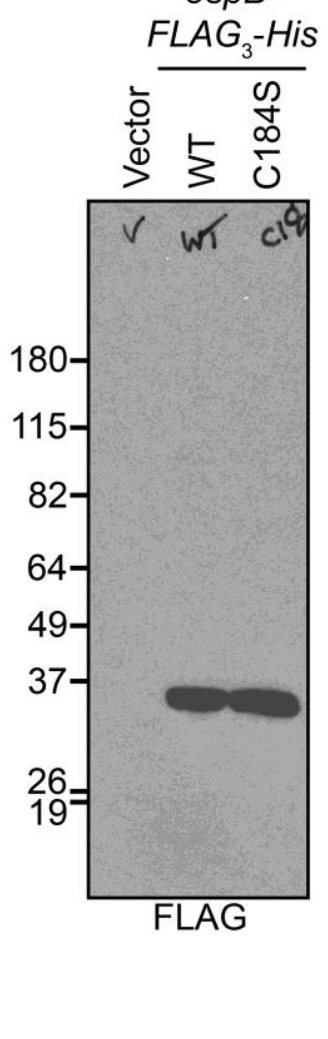

(c) myc-ospB

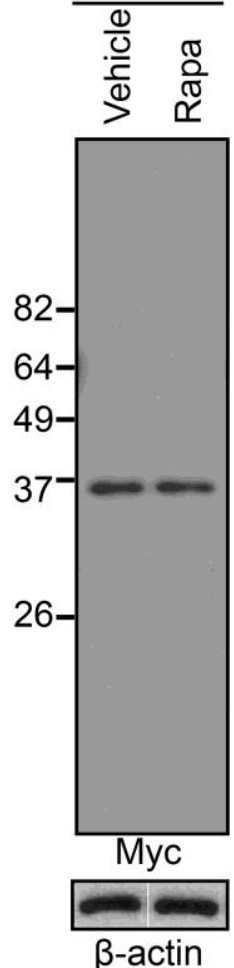

$\beta$-actin

Figure S1. Absence of evidence of processing of OspB in cell lysates. (a) Wild type OspB and

OspB (C184S) expressed in yeast, detected by immunoblotting with anti-OspB and anti-FLAG

antibodies after separation on a 15\% SDS-PAGE gel. $\alpha$-tubulin serves as a loading control. (b)

Samples from panel (a) separated on a 7.5\% SDS-PAGE gel and probed as in panel (a). (c)

Transfection of mouse embryonic fibroblasts with pCMV-myc-ospB. Cells were treated with rapamycin $(10 \mathrm{nM})(+)$ or a DMSO vehicle control. Myc-OspB detected by immunoblotting with an anti-myc antibody after separation on a 10\% SDS-PAGE gel. $\beta$-actin serves as the loading control; 
bioRxiv preprint doi: https://doi.org/10.1101/2021.09.01 458261; this version posted September 1,2021 . The copyright holder for this preprint (which was not certified by peer review) is the author/funder, who has granted bioRxiv a license to display the preprint in perpetuity. It is made available under aCC-BY 4.0 International license.

519 Table S1: Yeast genes whose over-expression suppresses OspB-mediated growth inhibition of $S$.

520 cerevisiae in the presence of caffeine.

521 The functions of the gene products are from the Saccharomyces genome database (Cherry et al., 2012).

522 Genes are listed alphabetically by name.

\begin{tabular}{|c|c|c|}
\hline Name & Gene & Function of gene product \\
\hline BRE1 & $Y D L 074 C$ & E3 ubiquitin ligase \\
\hline CLN3 & YAL040C & Regulatory subunit of cyclin-dependent protein kinase \\
\hline COS3 & YML132W & Membrane protein turnover \\
\hline CSM1 & YCR086W & Nucleolar protein involved in meiosis \\
\hline CYC3 & YAL039C & Holocytochrome $c$ synthase \\
\hline DDII & YER143W & SNARE-binding protein \\
\hline DDPl & YORI63W & Inositol pyrophosphate pathway phosphatase \\
\hline EMA17 & YIL029C & Putative protein of unknown function \\
\hline FMT1 & $Y B L 013 W$ & Methionyl-tRNA formyltransferase \\
\hline GAL11 & YOL051W & Subunit of RNA polymerase II mediator complex \\
\hline HIS3 & YOR202W & Histidine biosynthesis \\
\hline HSP60 & YLR259C & Mitochondrial chaperonin \\
\hline$J J J 3$ & YJR097W & Putative protein of unknown function \\
\hline LAT1 & $Y N L 071 \mathrm{~W}$ & Subunit of pyruvate dehydrogenase complex \\
\hline$L S B 1$ & YGR136W & Negative regulator of actin nucleation \\
\hline MTC6 & YHR151C & Putative protein of unknown function \\
\hline$P B Y 1$ & YBR094W & Putative tubulin tyrosine ligase \\
\hline PPE1 & YHR075C & Carboxyl methyl esterase \\
\hline$P R X 1$ & $Y B L 064 C$ & Mitochondrial thioredoxin peroxidase \\
\hline PTC3 & YBLO56W & Type 2C protein phosphatase (PP2C) \\
\hline QCR6 & YFR033C & Subunit of cytochrome $b c_{1}$ complex \\
\hline
\end{tabular}


bioRxiv preprint doi: https://doi.org/10.1101/2021.09.01458261· this version posted September 1,2021 . The copyright holder for this preprint (which was not certified by peer review) is the author/funder, who has granted bioRxiv a license to display the preprint in perpetuity. It is made available under aCC-BY 4.0 International license.

\begin{tabular}{|l|l|l|}
\hline RIM11 & YMR139W & Protein kinase \\
\hline SEC3 & YER008C & Subunit of the exocyst complex \\
\hline SIW14 & YNL032W & Inositol pyrophosphate pathway phosphatase \\
\hline SLX8 & YER116C & Subunit of SUMO-targeted ubiquitin ligase complex \\
\hline TCB1 & YOR086C & Endoplasmic reticulum-plasma membrane tethering \\
\hline TKL2 & YBR117C & Transketolase in the pentose phosphate pathway \\
\hline UBC1 & YDR177W & Ubiquitin conjugating enzyme \\
\hline UMP1 & YBR173C & Chaperone \\
\hline YUH1 & YJR099W & Thiol-dependent ubiquitin-specific protease \\
\hline- & YAR023C & Putative protein of unknown function \\
\hline- & YBL100C & Putative protein of unknown function \\
\hline- & YBR116C & Putative protein of unknown function \\
\hline- & YBR284W & Putative metal-dependent hydrolase \\
\hline
\end{tabular}

